\title{
Effects of Probiotic Bacillus subtilis on Intestinal Microbial Diversity and Immunity of Orange Spotted Grouper Epinephelus coioides
}

\author{
Anggraini Ratih Purwandari \\ Student of Double Degree Programme Brawijaya University and NSYSU \\ E-mail: Anggrainiratih57@yahoo.co.id \\ Prof. Houng Yung Chen \\ Institute of Marine Biology, National Sun Yat-Sen University, Taiwan
}

Received: March 22, 2013 Accepted: April 28, 2013 Published: May 18, 2013

doi: 10.5296/jab.v1i1.3714 URL: http://dx.doi.org/10.5296/jab.v1i1.3714

\begin{abstract}
Groupers are an important mariculture in Taiwan and Southeast Asian countries. The rapidly growing orange spotted grouper Epinephelus coioides has experienced relatively severe bacterial disease problems. The proliferation of pathogens in fish can be suppressed by commensal microbe. In this research, probiotic seem to offer an attractive alternative. Bacillus subtilis is a probiotic bacterium that is administered in diet to suppress proliferation of pathogens. In the present study, E. coioides were fed for 6 months with diets contain $B$. subtilis. Percent weight gain and feed efficiency of the fish fed diets containing $0.1 \%$ or $1 \%$ probiotics $(\mathrm{w} / \mathrm{w})$ were significantly better than the control. The innate cellular response, respiratory burst of the supplemental groups was significantly higher compared to the control on 10 or 20 days after feeding, and even more significant on 30 days. Probiotic B. subtilis increased the intestinal microbial diversity by stimulating the bacterial populations of Paenibacillus sp, Lactobacillus oeni strain 59 b, and Methilacidophilum infernorum strain V4 that are beneficial for E. coioides. The best dose of probiotic B. subtilis based on growth performances, innate cellular responses and microbial profile of fish intestines is $0.1 \%$, which showed equal efficacy as the $1 \%$ diet.
\end{abstract}

Keywords: Orange Spotted Grouper, Probiotics, Microbial, Immune Response, DGGE 


\section{Introduction}

It is recognized that the gastrointestinal microbes of homeothermic animals serve several functions, such as digestion and development of the mucosal system, angiogenesis, and as a protection barrier against disease (Schiffrin, 2002; Stevens, 1998). The majority of these microbes are present in the digestive tract communities. They contribute to the harvest of dietary nutrients that would otherwise be inaccessible (Bached et al., 2004; Sonnenburg et al., 2005). The potential benefit of the microbes is to influence the absorption of some nutrients, such as lipids. Thus, the establishment of a microbe is a key component in order to health by competitive mechanisms and immune system development and maturation. By facilitating the growth of protective bacteria that will compete against the opportunistic pathogens for food and adhesions sites to intestinal membrane, they can prevent the pathogens entering the body. An important aspect is the specificity of the host response, which depends on the bacteria species colonizing the digestive tract. Therefore it is important to know the composition of this microbe in fish and the effects which different factors could have on it, especially in the case of fish culture with high economical interest such as E. coioides. The problem of this kind of studies is that culture techniques are laborious and less accuracy because all bacteria in the intestines only culturable bacteria that can be identified by this method. An alternative way to overcome these disadvantages in studying the composition of intestinal microbes is by molecular methods, polymerase chain reaction-denaturing gradient gel electrophoresis (PCR-DGGE).

The intestinal microbe is an important component of mucosal barrier has resulted in the promotion of the use of beneficial probiotic (Gomes, 2008). Most of the studies with probiotic used the vegetative cells that possess the probiotic functions. The present study used endospores of B. subtilis, because endospore can be stored in long time, more stable in high temperature and $\mathrm{pH}$, and resistant to feed pelletization.

The aim of research was determined growth performance, profile of the intestinal microbes and immune responses of orange spotted grouper E. coioides when fed on three different diets supplemented with different concentrations of probiotic B. subtilis.

\section{Materials and Methods}

The details of the dietary treatments, growth trial, measurements of growth performances, microbial examinations, DGGE method are described in Purwandari (2012). Growth Performances, Microbial numbers and immune responses data were analyzed by two-way of analysis of variance followed by tukey, significant differences were declared at $\mathrm{P} \leq 0.05$. DGGE profiles were scanned using LAS 3000 machine. The number of DGGE bands were calculated with software quantity one based on appearances of the bands each lane. Similarities between the PCR-DGGE banding patterns were analyzed using quantity one 4.6.2 software. The DGGE patterns were achieved by construction of dendograms using the Unweighted Pair Groups Method using Arithmetic Averages (UPGMA). The unweighted pair group method with arithmetic average (UPGMA) was used to create a dendogram representing the similarity of the microbial profiles from the DGGE fingerprints. The diversity of whole microbial community was determined by Shannon index $\left(\mathrm{H}^{\prime}\right)=-\Sigma$ pi ln pi, 
pi is proportion of each species in the sample times. The richness was calculated based on the formula Margalef's richness index: $(\mathrm{S}-1) / \ln (\mathrm{n}), \mathrm{S}$ is the total number of species. Evenness was determined by Pielou's evenness index: J'= H'/ H'max, which $\mathrm{H}^{\prime}=$ shannon index and $\mathrm{H}^{\prime} \max$ $=\ln \mathrm{S}$.

\section{Results}

\subsection{Growth Measurements}

Percent weight gain (PWG) of groupers fed $0.1 \%$ and $1 \%$ diets probiotic B. subtilis were significantly higher than the control from 0 to 2,4 , and 6 month of feeding (Table 1). PWG of the grouper were not significantly different among the dietary treatments for the period of 3-4 months.

Feed efficiencies (FEs) of fish fed $1 \%$ and $0.1 \%$ diets were significantly higher than the control diet of feeding. After 2 months of feeding the FEs of fish fed the control, $0.1 \%$ and $1 \%$ diets were $3.8 \pm 0.1,2.2 \pm 0.1$ and $2.1 \pm 0.0$, respectively. FEs of the grouper were not significantly different among the dietary treatments for the period of 3-4 months. FEs of fish fed the control, $0.1 \%$ and $1 \% \mathrm{~kg}$ diets were $1.8 \pm 0.1,1.4 \pm 0.1$ and $1.5 \pm 0.1$.

Table 1. Percent weight gain (PWG) of groupers

\begin{tabular}{|c|c|c|c|}
\hline \multirow[t]{2}{*}{ Times of feeding (month) } & \multicolumn{3}{|c|}{ Treatment of diets by probiotic $B$. Subtilis $\left(\% \mathrm{~kg}^{-1)}\right.$} \\
\hline & Control (0) & 0.1 & 1 \\
\hline $0-2$ & $26.4 \pm 2.2$ & $41.6 \pm 2.6^{\mathrm{s}}$ & $43.6 \pm 1.8^{\mathrm{s}}$ \\
\hline $3-4$ & $46.2 \pm 3.4^{\mathrm{ns}}$ & $59.5 \pm 3.4^{\mathrm{ns}}$ & $57.8 \pm 5.5^{\mathrm{ns}}$ \\
\hline $5-6$ & $95.6 \pm 8.2$ & $118.5 \pm 9.8^{\mathrm{s}}$ & $129.4 \pm 12.9^{\mathrm{s}}$ \\
\hline
\end{tabular}

Mean body weights of the groupers were not significantly different at the end of 2, 4 and 6 months. At the end of the 6 months feeding, the mean body weight of fish fed the control, $0.1 \%$ and $1 \%$ diets were $43.4 \pm 1.8,47.6 \pm 2.5$ and $48.5 \pm 2.0 \mathrm{~g}$, respectively.

Survival rate of the groupers were not significantly different at the end of 2, 4 and 6 months. At the end of the 6 months, the survival rate of fish fed the control, $0.1 \%$ and $1 \%$ diets were $85.6 \pm 4.8 \%, 94.4 \pm 1.1 \%$ and $88.9 \pm 2.2 \%$, respectively.

\subsection{Total Viable Count of Sea Water Tank}

The initial number of Log Total Viable Count (Log TVC) in the culture tank before the treatment was $3.48\left(2.99 \times 10^{3}\right) \mathrm{cfu} \mathrm{ml}^{-1}$. Addition of probiotic Bacillus subtilis caused changes in Log TVC level. Log TVC was increased with increasing culture time. The Log TVC in the tank of $1 \%$ and $0.1 \%$ diet were significantly higher than the tank with the control diet. The Log TVC in the control, $0.1 \%$ and $1 \%$ after 10,20 , and 30 days feeding were showed on Table 2. 
Table 2. Total bacteria in the tank culture

\begin{tabular}{|c|c|c|c|}
\hline \multirow{2}{*}{ Time (day) } & \multicolumn{3}{|c|}{ Log Total Viable Count (TVC) $\left(\mathrm{cfu} \mathrm{m}^{-1}\right)$} \\
\hline & Control $(0)$ & $0.1 \%$ & $1 \%$ \\
\hline 10 & $3.29\left(\log 2.02 \times 10^{3}\right)$ & $3.73\left(\log 5.71 \times 10^{3}\right)$ & $4.06\left(\log 1.34 \times 10^{4}\right)$ \\
\hline 20 & $3.35\left(\log 2.26 \times 10^{3}\right)$ & $4.10\left(\log 1.45 \times 10^{4}\right)$ & $4.18\left(\log 1.80 \times 10^{4}\right)$ \\
\hline 30 & $3.81\left(\log 7.22 \times 10^{3}\right)$ & $4.34\left(\log 4.56 \times 10^{4}\right)$ & $4.22\left(\log 3.31 \times 10^{4}\right)$ \\
\hline
\end{tabular}

The population level of viable bacteria was somewhat higher in $1 \%$ probiotic tank on all accession time, then followed by $0.1 \%$ probiotic tank on accession time 30 days and 20 days feeding period. The highest log total viable was $0.1 \%$ probiotic treatment on accession time 30 days of feeding period. The lowest log total viable bacteria in sea water tank were the control group on accession time 10 days of feeding period.

\subsection{Immune Parameters}

\subsubsection{Respiratory Burst}

The respiratory burst that fed a diet containing 1 and $0.1 \%$ diet was significantly higher than the control. There was a significant increase in respiratory burst from day 20 to day 30 , especially the 1 and $0.1 \%$.

The respiratory burst for fish that fed the $1 \%$ diet on all elapsed time was highest value, followed by the $0.1 \%$ (Figure 4 ). The respiratory burst values for fish that fed the $1 \%$ diet for 10,20 , and 30 days were $1.98 \pm 0.03,2.12 \pm 0.24$ and $5.03 \pm 0.02$, respectively. Those for the $0.1 \%$ diet were $1.91 \pm 0.01,2.12 \pm 0.16$, and $3.52 \pm 0.03$, respectively. And the control were $1.87 \pm 0.03,1.83 \pm 0.12$, and $2.01 \pm 0.15$, respectively.

\subsubsection{Leucocyte Proliferation}

The leucocyte proliferation of fish that fed the $1 \%$ and $0.1 \%$ diet was not significantly different than the control. The feeding time of 10, 20 and 30 days did not show significant difference in leucocyte proliferation among treatments. The leucocyte proliferation for day 20 was higher compare to days 10 and 30 . The leucocyte proliferation for the $1 \%$ at day 20 was highest.

The leucocyte proliferation for fish that fed the Control diet were $1.31 \pm 0.09,1.50 \pm 0.19$, and $1.10 \pm 0.02$ when fed the experimental diets for 10,20 , and 30 days. Those for the $0.1 \%$ diet were $1.25 \pm 0.09,1.59 \pm 0.22$, and $1.21 \pm 0.02$, respectively. And those for the $1 \%$ diet were $1.10 \pm 0.02,1.88 \pm 0.09$ and $1.21 \pm 0.13$, respectively.

\subsection{PCR product Separated on Agarose gel}

After the PCR amplification, fragment about $433 \mathrm{bp}$ obtained from all fish intestine samples were fragments of $16 \mathrm{~S}$ rDNA V6-V8 regions. Figure 1 showed the results of the $16 \mathrm{~S}$ rDNA fragments amplified by PCR and separated on 1.2\% agarose gel. It is shown that lanes I1 and I2 were the initial intestine. Lanes $\mathrm{C}, \mathrm{P}$, and $\mathrm{B}$ were the control, $0.1 \%$, and $1 \%$ dietary, 
respectively. 10, 20, and 30 were elapsed times of feeding periods.

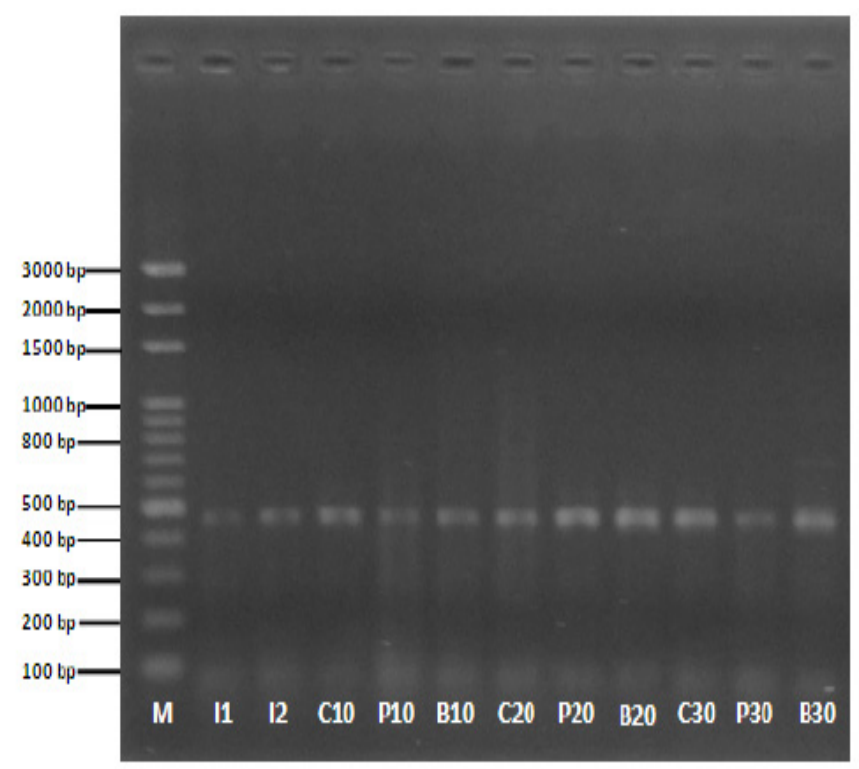

Figure 1. 16S rDNA amplified by PCR separated on 1.2\% agarose gel. Lanes I1 and I2 are the initial intestine. Lanes $\mathrm{C}, \mathrm{P}$, and $\mathrm{B}$ are the control, $0.1 \%$, and $1 \%$ dietary, respectively. 10 , 20 and 30 are elapsed time of feeding periods

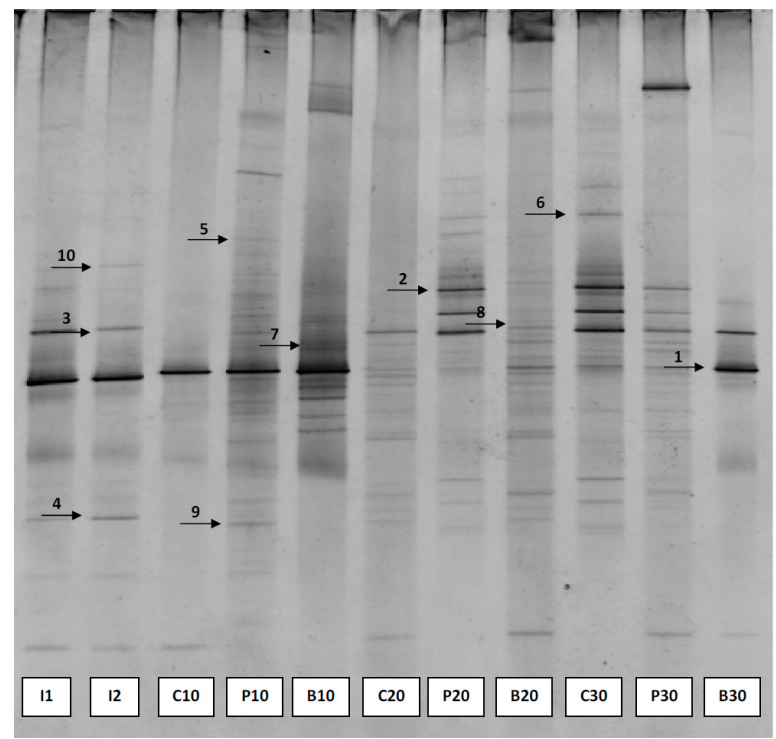

Figure 2. The result of DGGE analysis of $16 \mathrm{~S}$ rDNA fragments. The products of bacterial DNA in fish intestines amplified by PCR were separated by DGGE. Lanes I1 and I2 are the initial fish. Lanes C, P, and B are the control, $0.1 \%$, and $1 \%$ dietary groups, respectively. 10 , 20 and 30 are elapsed time, respectively 


\section{Macrothink}

DGGE analysis of gut microbial communities is presented in Figure 3. In order to compare all profiles UPGMA was used to create a dendogram describing pattern similarities. DGGE profiles of the experimental were relatively low similar to the control, similarity $<40 \%$. The total number of bands was higher in the supplemental group than control on day 10 and day 20 , and lower in day 30. Shannon index on probiotic groups higher than control on day 10 and and day 20, and lower in day 30. Same result reported on richness, the probiotic higher than control on day 10 and day 20, and lower in day 30. Evenness (values close to 1 represents less variation in communities) shows that variation in the communities with the respective groups vary greatly (Table 3 ).

Table 3. Microbial parameters from DGGE fingerprints of gut microbiota of the groupers fed the experimental diets contains different levels $(0,0.1 \%, 1 \%)$ of probiotics

\begin{tabular}{ccccc}
\hline Probiotic (\%) & $\begin{array}{c}\text { Total number of } \\
\text { band }(\mathrm{R})^{\mathrm{a}}\end{array}$ & Diversity $^{\mathrm{b}}$ & Richness $^{\mathrm{c}}$ & Evenness $^{\mathrm{d}}$ \\
\hline 10 Day & & & & \\
0 & 5 & 0.13 & 0.76 & 0.19 \\
0,1 & 24 & 0.71 & 4.46 & 0.52 \\
1 & 15 & 0.40 & 2.71 & 0.30 \\
20 Day & & & & \\
0 & 17 & 0.50 & 3.10 & 0.40 \\
0,1 & 20 & 0.60 & 3.68 & 0.45 \\
1 & 23 & 0.77 & 4.26 & 0.57 \\
30 Day & & & & \\
0 & 21 & 0.58 & 3.17 & 0.37 \\
0,1 & 18 & 0.58 & 3.30 & 0.46 \\
1 & 9 & 0.30 & 1.55 & 0.31 \\
\hline
\end{tabular}

\footnotetext{
${ }^{\mathrm{a}}$ Total number of band each sampling.

${ }^{\mathrm{b}}$ Shannon diversity index $(\mathrm{H}+)-\sum$ pi $\ln$ pi.

${ }^{c}$ Margelefs richness index (S-1)/ $\ln (\mathrm{n})$.

'Pielou's evenness index: $\mathrm{j}-\mathrm{H}+/ \mathrm{H}$ max.
} 


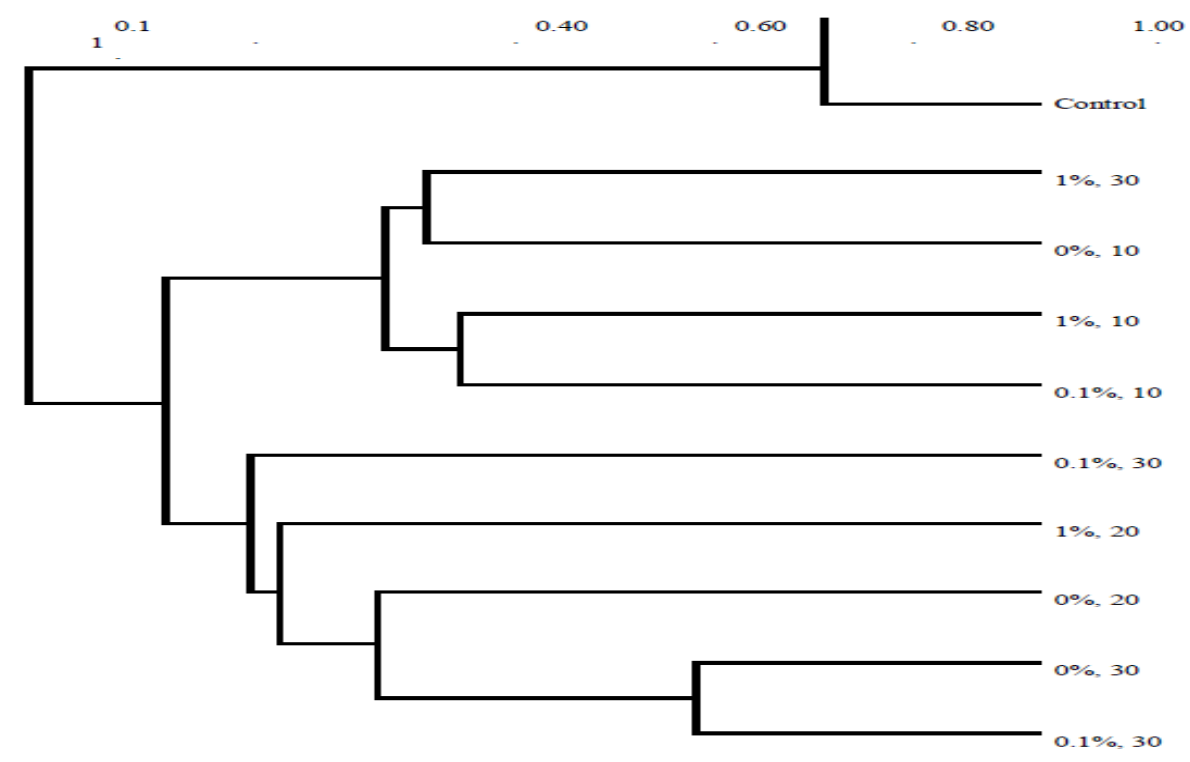

Figure 3. Unweighted pair group clustering dendogram of DGGE profiles using arithmetic average linkage. Arithmetic average linkage was contructed using quantity one 4.6.2.

software

\subsection{Sequences for Selected Clones}

A total of 136 clones inserted from cloning process were amplified use PCR and gotten 80 clear PCR products. Then the clear PCR products were loaded in DGGE gel to know the position each clone in the DGGE check. Sequences samples were selected by obtaining different position of each samples compare to the marker. Finally a total of 10 bands (band 1-10) were successfully sequenced from selected clones. Figure 4 showed that the 10 identified bacteria were closely related to one of the following four groups: Proteobacteria (13.77\%), Firmicutes (53.48\%), Verrumicrobia (29.3\%), and Archaea (3.45\%).

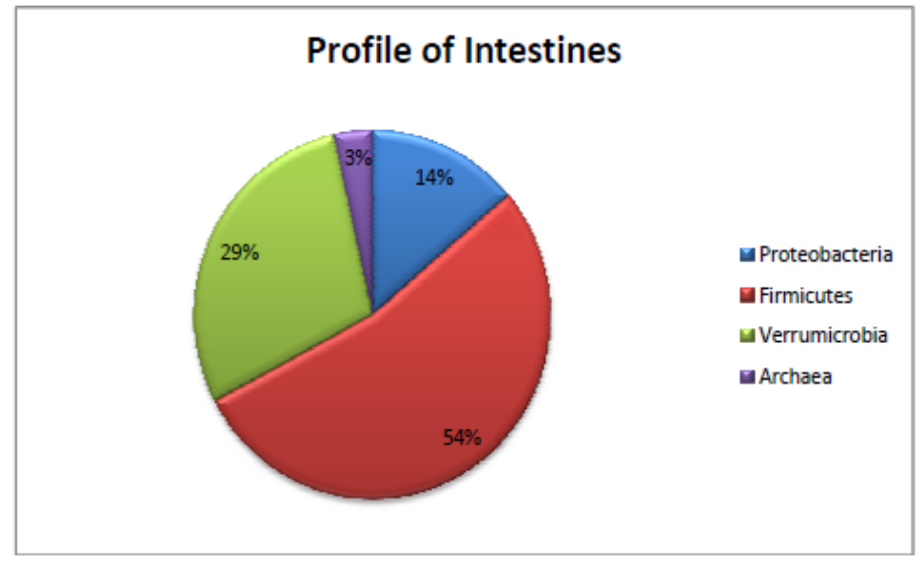

Figure 4. Intestinal microbial profile of Epinephelus coioides determined from DGGE analyses 
M. salsuginis strain MR was present in all samples, indicating that the bacteria were predominant bacteria. Each site also had its special species, for example Paenibacillus sp always existed in $0.1 \%$ probiotic sites on each elapsed time. Akkermansia muciniphila strain BAA-835 existed on all the sites, exception for treatment with elapsed time 10 day of feeding. Francisella noatunensis strain Ehime-1 only existed in the initial sites I1 and I2. Also Lactobacillus parafarraginis strain NRIC 0677 were found in the initial sites too, indicating that $F$. noatunensis strain Ehime-1 and Lactobacillus parafarraginis strain NRIC 0677 were origin species. Lactobacillus oeni strain $59 \mathrm{~b}$ only existed on probiotic $0.1 \%$ on elapsed times 10 and 20 days of feeding sites P10 and P20, respectively. And Methilacidophilum infernorum strain V4 only existed on probiotic sites P10, B10, B20, P30 and B30 for each elapsed time. This indicated that different diet were a resulted in different population of bacteria. The different diet had a great influence on the structure of bacteria.

\section{Discussion}

The research showed that probiotic $B$. subtilis at $0.1 \%$ or $1 \%$ significantly enhanced percent weight gain (PWG) and feed efficiencies (FE) than the control in the first feeding period. Liu et al. (2012) who showed that B. subtilis supplemented diet significantly higher growth than that of grouper fed the control diet after 28 days of feeding.

PWG and FEs of the grouper were not significantly different among those fed different levels of probiotics diets for subsequent 2 months. During this time period, the water temperature decreased. Temperature has a fundamental effect on animal physiology. It has long been known that environmental temperature affects all physiological functions of poikilothermic animals, such as fish (Bowden, 2008). The authors reported that weight gain significantly decreased in fish when treated in decreased temperature $\left( \pm 19^{\circ} \mathrm{C}\right)$. Low temperature might suppress the fish growth, rendering no significant difference among treatments even the effects of probiotic.

PWG and FEs of groupers fed $0.1 \%$ and $1 \%$ diets were once again significantly higher than the control group in the subsequent 2 months. The water temperature averaged $\pm 24^{\circ} \mathrm{C}$ during the period. Liu et al. (2012) reported that grouper E. coioides fed diet containing B. subtilis at $104-108 \mathrm{cfu} \mathrm{g}^{-1}$ had significantly increased PWG levels and FEs. (Sun et al., 2010) also reported that feed efficiency significantly increased in E. coioides fed Bacillus pumilus or B. clausii-containing diets during the experiment period. Several Bacillus species can secrete a wide range of exogenous enzymes to break down nutrient such as protein and carbohydrates (Liu et al., 2009; Ochoa et al., 2006; Farzanfar, 2006). They conclude that better growth performance in fish might have led to improve protein digestion. In the result that grouper $E$. coioides fed diets containing B. subtilis at $0.1 \%$ and $1 \%$ had significantly increased PWG levels and FEs, and this increased with the supplemented concentration of B. subtilis in the diets, which might have resulted from contributions of nutrients supplements and exogenous enzymes by $B$. subtilis.

The survival of the grouper were not significantly different during the 6 months trial when fed diets supplemented with probiotics Bacillus subtilis $0.1 \%$ and $1 \%$ or control diet. Zokaeifar et al. (2012), who reported that no significantly different on survival rate of white 
shrimp L. vannamei fed with Bacillus subtilis at doses $105 \mathrm{cfu} \mathrm{g}^{-1}$ and control diets. But survival rate was significantly higher when the $L$. vannamei were fed diets with B. subtilis at doses $108 \mathrm{cfu} \mathrm{g}^{-1}$.

Dietary supplementation of probiotic Bacillus subtilis caused changes in Log TVC of culture water. The $\log$ of viable bacteria in the $1 \%$ and $0.1 \%$ diet tanks were significantly higher compare to the control diet tank, and the log TVC were increased as the culture time increased. In this research additional spore of B. subtilis to the diets of E. coioides was more effective because of TVC in the control tank was also less compare to the probiotic tanks. The same research also reported by Panigrahi et al. (2004), who reported administration probiotic Lactobacillus rhamnosus in rainbow trout $O$. mykiss was more lower in TVC of the control tank compare to the probiotic tanks.

The respiratory burst that fed a diet containing $1 \%$ and $0.1 \%$ probiotic Bacillus subtilis was significantly higher compare to control ( $0 \%$ probiotic $B$. subtilis), especially at the elapsed time of 30 days. That's mean probiotic diet increases innate cellular response such as respiratory burst. Same results also reported by (Chiu et al., 2010). They reported respiratory burst of fish fed the 103,105, and $107 \mathrm{cfu} \mathrm{kg}^{-1}$ of $S$. cerevisiae diets were significantly higher than those of fish fed the control diet after 2 and 4 weeks of feeding. Same results are also demonstrated in a study about effects of potential probiotic B. subtilis T13 in juvenile sea cucumber Apostichopus japonicas (Zhao et al., 2012). Several authors also reported the increases in respiratory burst activity in cobia, rainbow trout, and $P$. vannamei by probiotics (Geng et al., 2011; Nikoskelainen et al., 2003; Gullian et al., 2004; Brunt \& Austin, 2005; Aubin et al., 2005).

The leucocyte proliferation of head kidney of the $1 \%$ and $0.1 \%$ probiotic was not significantly different compare to the control group after 10, 20 or 30 days of feeding. Similar lack of significant leucocyte proliferation was also reported by Panigrahi et al. (2004), who showed no significantly difference for leucocyte proliferation in rainbow trout $O$. mykiss fed with Lactobacillus rhamnosus at $109 \mathrm{cfu} \mathrm{g}^{-1}$. The significantly different only resulted with the doses $1011 \mathrm{cfu} \mathrm{g}^{-1}$. It is possible that $1 \%$ and $0.1 \%$ supplementation maybe insufficient to be effective in promoting leucocyte proliferation.

Extracting total DNA from bacteria in fish intestine is more rapid and accurate than traditional microbial separation and identification methods, and can reflect the diversity of bacteria in fish intestines more directly. It is viable to research the structure of bacteria in fish intestines by amplifying 16SrDNA of bacteria and separating the PCR products with DGGE. More information about these bands could be obtained. Longer 16SrDNA fragments can be obtained by improving the primers used in PCR and can be used to decide the taxonomic species effectively, and to study the structure of bacteria in fish intestines. At the same time, conditions of unculturable bacteria can be acquired, and the real environmental situation of fish intestine can be reflected. Such information is important for aquaculture to ensure the diversity of fish intestine.

Administration of probiotic $0.1 \%$ and $1 \%$ in the fish feed increased the numbers of microbial spesies after 10 and 20 day of feeding period. On day 30 however, the number of species for 
the control and $0.1 \%$ diets after 20 day feeding period, was greater than the $1 \%$ diet. The data also demonstrated that probiotic B. subtilis increased the microbial diversity (visible band number and Shannon diversity index) of E. coioides. That was in line with Kaup (1858) dietary administration of fresh or lyophilized probiotic Shewanella putrefaciens Pdp 11 for 60 days exerted an important influence on intestinal bacterial DGGE profiles and yielded a faster stabilization of the bacterial community in flat fish Solea senegalensis. This suggested that long-term supplementation of probiotic $B$. subtilis exerted significant effect on microbial composition of Epinephelus coioides. Therefore the stimulation of B. subtilis may be beneficial to the host. This result is in line with Yang et al. (2011), who showed a positive effect for dietary administration of probiotic Psychrobacter sp. SE6 on autochthonous microbiota in the GI tract of $E$. coioides.

In the recent study, from the total bacteria that were identified show that Francisella noatunensis strain Ehime-1 and Lactobacillus parafarraginis strain NRIC 0677 were only existed in the initial sites I1 and I2. Indicating that Francisella noatunensis strain Ehime-1 and Lactobacillus parafarraginis strain NRIC 0677 were origin species. And for the species Methylobacterium salsuginis strain MR and Akkermansia muciniphila strain BAA-835 were present in all samples; indicate that those bacteria were predominant bacteria. Dietary administration of probiotic Bacillus subtilis improved microbial diversity by stimulating the growth of another bacteria like Paenibacillus sp, Lactobacillus oeni strain $59 \mathrm{~b}$, and $M$. infernorum strain V4. Paenibacillus $s p$ have capability to symbiosis with other bacteria like obligate bacterial symbiont against pathogens (Enright et al., 2003). Lactobacillus oeni strain $59 \mathrm{~b}$ have a role in Malolactic fermentation process for increases microbiological stability and improves organoleptic characteristics (Lazaro et al., 2009). And Methylobacterium aminovorans strain JCM 8240 have a role to digest methanol, D-fructose, glycerol, ethanol, monomethylamine, dimethylamine, trimethylamine, TMAH, formamide, N-methylformamide, DMF, succinic acid, L-asparatic acid, L-glutamic acid, and betaine (Urakami et al., 1993). This indicated that dietary administration probiotic B. subtilis were stimulated another bacterial species that beneficial for E. coioides.

\section{Conclusions}

The growth performances of grouper E. coioides feds diets containing B. subtilis at $0.1 \%$ and $1 \%$ are significantly better than the contro in terms of PWG and FEs. The dietary supplementation of $1 \%$ and $0.1 \%$ probiotic also increased innate cellular response for respiratory burst and were significantly higher than the control, with the highest responses at day 30. Probiotic B. subtilis exerted different profiles of microbial diversity and stimulated another bacterial species like Paenibacillus sp, Lactobacillus oeni strain $59 \mathrm{~b}$, and Methilacidophilum infernorum strain V4. The best dose of probiotic B. subtilis for optimal cellular responses is thus $0.1 \%$, that was as efficient as the $1 \%$ treatment.

\section{References}

Aubin, J., Gatesoupe, F. J., Labbé, L., \& Lebrun, L. (2005). Trial of probiotics to prevent the vertebral column compression syndrome in rainbow trout (Oncorhynchus mykiss Walbaum). Aquaculture Research, 36, 758-767. http://dx.doi.org/10.1111/j.1365-2109.2005.01280.x 
Backhed, F., Ding, H., Wang, T., Hooper, L. V., Koh, G. Y., Nagy, A., ... Gordon, J. I. (2004). The gut microbiota as an environmental factor that regulates fat storage. Proceedings of the National Academy of Sciences USA 101, 15718-15723. http://dx.doi.org/10.1073/pnas.0407076101

Bowden, T. J. (2008). Modulation of the immune system of fish by their environment. Fish and Shellfish Immunology, 25, 373-383. http://dx.doi.org/10.1016/j.fsi.2008.03.017

Brunt, J., \& Austin, B. (2005). Use of a probiotic to control Lactococcosis and Streptococcosis in rainbow trout (Oncorhynchus mykiss Walbaum). Journal of Fish Diseases, 28, 693-701. http://dx.doi.org/10.1111/j.1365-2761.2005.00672.x

Cheng, A. C., Cheng, S. A., Chen, Y. Y., \& Chen, Y. J. (2009). Effects of temperature change on the innate cellular and humoral immune responses of orange-spotted grouper Epinephelus coioides and its susceptibility to Vibrio alginolyticus. Fish and Shellfish Immunology, 26, 768-772. http://dx.doi.org/10.1016/j.fsi.2009.03.011

Enright, M. R., \& Griffin, C. T. (2004). Specificity of association between Paenibacillus sp. and the entomopathogenic nematodes, Heterorhabditis spp. Microbial Ecology, 48, 414-423. http://dx.doi.org/10.1007/s00248-003-0166-0

Farzanfar, A. (2006). The use of probiotics in shrimp aquaculture. FEMS Immunology and Medical Microbiology, 48, 149-58. http://dx.doi.org/10.1111/j.1574-695X.2006.00116.x

Gomes, G. D., \& Balcazar, J. L. (2008). A review on the interactions between gut microbiota and innate immunity of fish. FEMS Immunology and Medical Microbiology, 52, 145-154. http://dx.doi.org/10.1111/j.1574-695X.2007.00343.x

Gullian, M., Thompson, F., \& Rodriguez, J. (2004). Selection of probiotic bacteria and study of their immunostimulatory effect in Penaeus vannamei. Aquaculture, 233, 1-14. http://dx.doi.org/10.1016/j.aquaculture.2003.09.013

Lazaro, L. M., Ferrer, S., Mora, R. R., \& Pardo, I. (2009). Lactobacillus oeni sp. nov., from wine. International Journal of Systematic and Evolutionary Microbiology, 59, 2010-2014. http://dx.doi.org/10.1099/ijs.0.007567-0

Liu, H., Liu, M., Wang, B., Jiang, K., Jiang, S., Sun, S., \& Wang, L. (2009). PCR-DGGE analysis of intestinal bacteria and effect of Bacillus spp on intestinal microbial diversity in kuruma shrimp (Marsupenaeus japonicas). Chinese Journal of Oceanology and Limnology, 28(4), 808-814. p://dx.doi.org/10.1007/s00343-010-9101-7

Liu, C. H., Chiu, C. S., Ho, P. L., \& Wang, S. W. (2012). Improvement in the growth performances of white shrimp, Litopenaeus vannamei, by a protease-producing probiotic, Bacillus subtilis E20, from natto. Journal of Applied Microbiology, 107, 131-141.

Nikoskelainen, S., Ouwehand, A. C., Bylund, G., Salminen, S., \& Lilius, E. M. (2003). Immune enhancement in rainbow trout (Oncorhynchus mykiss) by potential probiotic bacteria (Lactobacillus rhamnosus). Fish Shellfish Immunol, 15, 443-452. http://dx.doi.org/10.1016/S1050-4648(03)00023-8 


\section{Macrothink}

Ochoa, S. J. L., \& Olmos-Soto, J. (2006). The functional property of Bacillus for shrimp feeds. Food Microbiology, 23, 519-25. http://dx.doi.org/10.1016/j.fm.2005.10.004

Panigrahi, A., Kiron, V., Kobayashi, T., Puangkaew, J., Satoh, S., \& Sugita, H. (2004). Immune responses in rainbow trout Oncorhynchus mykiss induced by a potential probiotic bacteria Lactobacillus rhamnosus JCM 1136. Veterinary Immunology and Immunopathology, 102, 379-388. http://dx.doi.org/10.1016/j.vetimm.2004.08.006

Schiffrin, E., \& Blum, S. (2002). Interaction between the microbiota and intestinal mucosa. European Journal of Clinical Nutrition, 56, 60-64. http://dx.doi.org/10.1038/sj.ejen.1601489

Sonnenburg, J. L., Xu, J., Leip, D. D., Chen, C. H., Westover, B. P., Weatherford, J., ... Gordon, J. I. (2005). Glycan foraging in vivo by an intestine-adapted bacterial symbiont. Science, 307, 1955-1959. http://dx.doi.org/10.1126/science.1109051

Stevens, C., \& Hume, I. (1998). Contribution of microbes in vertebrate gastrointestinal tract to production and conservation of nutrients. Physiological Riviews, 78, 393-427.

Urakami, T., Araki, H., Suzuki, K. I., \& Komagata, K. (1993). Further studies of the genus Methylobacterium and description of Methylobacterium aminovorans sp. nov. International $\begin{array}{lllll}\text { Journal of Systematic } & \text { Bacteriology, } & 43, & \end{array}$ http://dx.doi.org/10.1099/00207713-43-3-504

Yang, H. L., Sun, Y. Z., Ma, R. L., Li, J. S., \& Huang, K. P. (2011). Probiotic Psychrobacter sp. improved the autochthonous microbial diversity along the gastrointestinal tract of grouper Epinephelus coioides. Journal Aquaculture Research Development.

Zhao, Y., Zhang, W., Xu, W., Mai, K., Zhang, Y., \& Liufu, Z. (2012). Effects of potential probiotic Bacillus subtilis T13 on growth, immunity and disease resistance against Vibrio splendidus infection in juvenile sea cucumber Apostichopus japonicas. Fish and Shellfish Immunology, 32, 750-755. http://dx.doi.org/10.1016/j.fsi.2012.01.027

\section{Copyright Disclaimer}

Copyright reserved by the author(s).

This article is an open-access article distributed under the terms and conditions of the Creative Commons Attribution license (http://creativecommons.org/licenses/by/3.0/). 